\title{
Effectiveness of planned teaching program on knowledge and knowledge on practice regarding prevention of common infections among mothers of infants at Kovilpalayam, Coimbatore.
}

\author{
Mr. Yogesh Kumar, \\ RN. RM. M.Sc. (Nursing) Associate Professor, Dept. Child Health Nursing, Maharishi Markandeshwar College \\ of Nursing, Maharishi Markandeshwar University, Mullana, Ambala.
}

\begin{abstract}
:
Background: A child is the greatest treasure of mankind. His health, wellbeing, safety and future are in the hands of his parents from birth until he is on his own. The first year of life is crucial laying the foundation of good health. At this time certain specific care and precautions are essential to ensure the survival of healthy development of the child to a future adult.

Methods: One group pretest and posttest experimental design was adopted for this study. The sample for this study consisted of 40 mothers of infants selected by non probability Purposive sampling technique. A structured interview schedule was used to assess the knowledge and knowledge on practice among mothers regarding prevention of common infections among infants.

Results: The sample comprised of 40 mothers of infants in this study. Inferential statistics and descriptive statistics were used to analyze the data. To obtained 't' value for knowledge was 15.95 at $(p<0.05)$ and for practice was at $11.46(p<0.05)$.

Conclusion: The results indicated that the knowledge of the mothers was significantly improved after planned teaching programme. Knowledge on practice of mothers also improved significantly as well.

Key words: Common Infections, Infants, knowledge, practice, Planned Teaching program.
\end{abstract}

\section{Introduction:}

Child's health, wellbeing, safety and future are in the hands of his parents from birth until he is on his own. Youngest children those from newborn to walking are called infants. The age from 0-12 months of life is known as infancy period. The future development of our infants depends on their enjoying good health today. A house is an exciting place for infants and small children, love to explore but aren't aware of the potential health hazards. Life can't be risk free, but most house hold infections can be prevented by positive awareness about the care of infants. Deficiencies of the immune system place the infants at risk for infection. Other conditions that decrease resistance are malnutrition, anemia, fatigue, and chilling of the body, even if the care givers smoke also increases the likelihood of infection. The infants under age three months have a lower infection rate, presumably because of the protective function of maternal antibodies. The infection rate increases from age three to six months this is the time between the disappearance of maternal antibodies and the infant's own antibody production.

The incidence of infections in rural community is very common in India, especially the infections in infants hence the knowledge of mothers is essential for undertaking measures to prevent them. The death rate is highest in the age group 0-4 years. This is the result of malnutrition and infection. About $21 \%$ of total deaths are estimated to be under the age group 0-1 year.

Most of the ten leading causes of death during infancy continue to occur during the prenatal period. The first four causes- congenital anomalies, sudden infant death syndrome, disorders relating to short gestation and unspecified LBW, and respiratory distress syndrome- accounted for just over half (54\%) of all deaths of infants under one year of age in 1999. The next six causes accounted for only $15 \%$ of all infants' deaths.

In developing countries, there are valid factors, which affect the health of infants. Adopting appropriate preventive measures and raising the level of knowledge of people, mainly mother. Lack of knowledge and awareness about prevention of infections in infants, which are influenced by illiteracy, low social class, psychological stress and unsafe environmental sanitation and decreased knowledge of mothers regarding infants care practices.

Teaching is most effective when it responds to a learners need. There is an important need to impart knowledge to the needy people about the infant care regarding prevention of common infections. Most of the minor infections in the infancy are unavoidable but major and serious infections can be prevented by adults caring for their children. Mothers play a major role in this process; hence the knowledge and practices of mother 
regarding prevention of common infections among infants should be improved by administering them the adequate awareness by teaching program.

In India, 26 million children are born every year one in nine will die before reaching the age of five in till 1993. The mortality rate was about $23 \%$ in children of $0-5$ years old and infant mortality rate was $74 \%$ in 1995 and it was 71\% in 1997and 53\% in 2000 and has reduced to 37.9/1000 live births in 2005 in Tamilnadu. The infant mortality rate was $49 \%$ due to combined effects of malnutrition and unhygienic environment and related infection. A WHO (2003) reported that, out of 52 million deaths from all causes in 2002, more than 17 million were due to infectious diseases, including about nine million deaths in young children under the age of one year.

\title{
II. Materials And Methods:
}

The effectiveness of planned teaching program on knowledge and knowledge on practice regarding prevention of common infections among mothers of infants was conducted at the Kovilpalayam which is $10 \mathrm{kms}$ away from Coimbatore city with the following objectives-

\section{Objectives:}

1. To assess the mothers knowledge and knowledge on practice regarding prevention of common infections among infants

2. To deliver the planned teaching program regarding prevention of common infections among infants

3. To find out effectiveness of the planned teaching program regarding prevention of common infections among infants

4. To find out the relationship between the knowledge and knowledge on practice regarding prevention of common infections among infants

5. To associate various variables and knowledge and knowledge on practice regarding prevention of common infections among infants

Experimental approach a subtype of quantitative approach was used for the present study. Quasi experiments involve the manipulation of an independent variable that is implementing of an intervention. The one group pretest posttest experimental research design was adopted in the study. In the present study a pretest was administrated by means of questionnaire method depicted as $0_{1}$, then a planned teaching program was delivered depicted as $\mathrm{X}$, and a post test was conducted by using the same questionnaire depicted as $0_{2}$.

\section{Population}

The population of present study is the mothers who have the infants, in Kovilpalayam during the period of data collection.

\section{Sample Size}

The sample size included for the study was 40 mothers who have infants.

\section{Sampling Technique}

Purposive sampling technique was used to select samples for the present study. The mothers of infants, who fulfilled the sample criteria, were selected till the sample size was obtained for the present study.

\author{
Sample Selection Criteria \\ Inclusive Criteria \\ $>$ Mothers of infants \\ $>$ Mothers who can communicate in Tamil \\ $>$ Mothers who are willing to participate \\ $>$ Mothers of any level of education \\ Exclusive Criteria \\ $>$ Mothers of more than 1 year of age children \\ Mothers whose infant has deformity or congenital anomalies \\ $>$ Mothers who belongs to health care departments
}

\section{Description of Tools}

The planned teaching program was developed after reviewing the literature and considering the opinion of Pediatric Nursing subject Experts, to measure the knowledge and practice of mothers regarding prevention of common infections among infants.

Planned teaching program consisting of Part-A, Distribution of Demographic Variables, includes the age of infant, gender of infant, total number of children, birth order of infant, age of mother, educational status of mother, type of family, income of family per month, and type of diet consumed by family. Part-B Questions Regarding Knowledge, consists of 30 multiple choice questions related to assessment of the knowledge of mothers regarding prevention of infection in infant. Each question had one correct answer and was given a score 
of 1 mark, for wrong answer a score of 0 mark was given the total score allotted for this section was 30. Part-C Questions Regarding Knowledge on practice consists of 20 questions related to assessment of the knowledge on practice of mothers regarding prevention of infection in infant. One mark was given for 'Yes' answer and zero mark for 'No' answer

\section{Content Validity}

The planned teaching program was given for assessing the validity to five experts specialized in pediatric nursing. The researcher met the expert for clarifications in various aspects of the research tool. Some modifications were made according to the expert suggestions.

\section{Reliability of the instrument}

The reliability of the questionnaire was found out by Spearman Brown Split half Technique. The reliability for the questionnaire related to knowledge of mothers regarding prevention of common infections among infants was +0.93 and questionnaire related to practice of mothers regarding prevention of common infections among infants was +0.75 which shows that the reliability of the tool was satisfactory.

Pilot Study

In order to test the relevance and practicability of the tool a pilot study was conducted among 5 mothers of infants. Data were analyzed to find out suitability and findings revealed that the study was feasible.

\section{Procedure for Data Collection}

Prior permission was obtained from Chief Medical Officer (CMO), PHC, S.S. Kulam, samples were selected by purposive sampling technique. The study was conducted within four weeks period. During first two weeks of study a pretest was conducted for 40 mothers of infants by administering the questionnaire, on the same day planned teaching program was delivered to the mothers for about 45 minutes regarding prevention of infections among infants by using various A.V. aids. The post test was conducted for these 40 mothers of infants following next two weeks, to find out the effectiveness of planned teaching program by administering the same questionnaire.

\section{Plan for Data Analysis}

Data were planned to be analyzed by using descriptive and inferential statistics, Descriptive statistics were used to analyze the frequency, percentage, mean and standard deviation of the variables.

Inferential statistics were used to determine the relationship and comparison to identify the difference

Chi- Square test was computed to find out the association between Knowledge and practice with selected demographic variables.

\section{Results:}

The collected data regarding the knowledge and practice of the mothers on prevention of infections among infants at the Kovilpalayam were organized and analyzed were as follows.

The findings based on the descriptive and inferential statistical analysis are as follows.

Table. 1 Distribution of Demographic Data

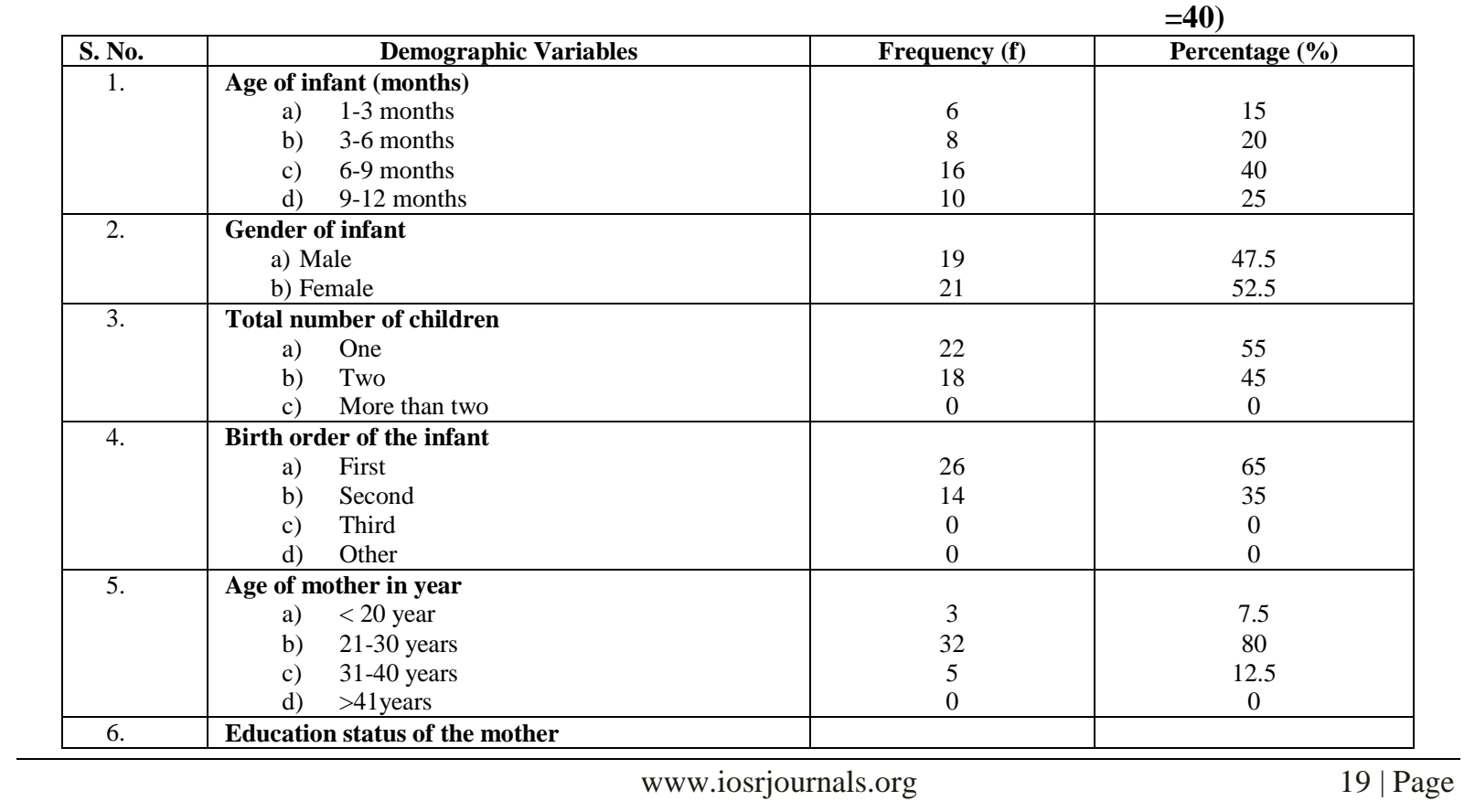


Effectiveness of planned teaching program on knowledge and knowledge on practice regarding

\begin{tabular}{|c|r|c|c|}
\hline & a) $\quad$ Illiterate & 3 & 7.5 \\
& b) Primary education & 19 & 47.5 \\
& c) Higher secondary & 17 & 42.5 \\
& d) Graduate and above & 1 & 2.5 \\
\hline 7. & Type of family & 27 & 67.5 \\
& a) Nuclear family & 13 & 32.5 \\
\hline 8. & b) Joined family & 32 & 80 \\
& Income of Family per month & 8 & 20 \\
& a) Less Rs.5000/- & 0 & 0 \\
& b) Rs.5001/- Rs.7000/- & 0 & 0 \\
\hline 9. & c) Rs.7001/- Rs.9000/- & & 27.5 \\
& d) Above Rs.9001/- & 11 & 72.5 \\
\hline
\end{tabular}

Table. 2 Distribution of Statistical Value of Pretest and Posttest Knowledge of the Mothers Regarding Prevention of Common Infections Among Infants

\begin{tabular}{|c|c|c|c|c|c|}
\hline S.No. & Knowledge & Mean & SD & 't'value & Level of Significance \\
\hline 1. & Pre test & 22 & 2.02 & \multirow{2}{*}{15.95} & $\mathrm{p}<0.05$ \\
\hline 2. & Post test & 27 & 1.64 & \\
\hline
\end{tabular}

Table 2 shows for 39 degree of freedom at $5 \%$ level of significance the table value of ' $t$ ' was 1.694 and the calculated value was 15.95 which is greater than the table value hence there was a significant difference existing between pre test and post value and it can be concluded that the knowledge has improved significantly. Hence alternative hypothesis was accepted.

Table. 3 Distribution of Statistical Value of Pretest and Posttest Knowledge on Practice of the Mothers Regarding Prevention of Common Infections Among Infants

$(\mathrm{n}=\mathbf{4 0})$

\begin{tabular}{|c|c|c|c|c|c|}
\hline S.No & Practice & Mean & SD & ' $t$ ' Value & $\begin{array}{c}\text { Level of } \\
\text { significance }\end{array}$ \\
\hline 1. & Pre test & 17 & 1.24 & 11.46 & $\mathrm{p}<0.05$ \\
\hline 2. & Post test & 19 & 0.80 & \multirow{2}{*}{. } \\
\hline
\end{tabular}

Table 3 shows for 39 degree of freedom at 5\% level of significance the table value of ' $t$ ' was 1.694 and the calculated value was 11.46 which was greater than the table value hence there was a significant difference existing between pretest and post test value and it can be concluded that the knowledge on practice has improved significantly. Hence alternative hypothesis was accepted.

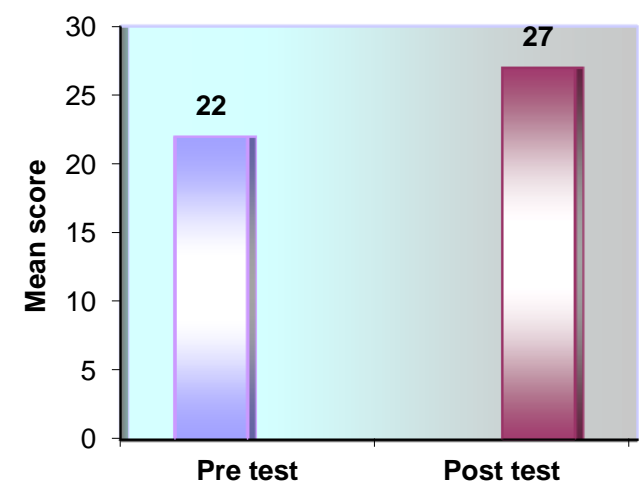

Figure. 1 Distribution of Pretest and Posttest Mean Score of Knowledge of Mothers 


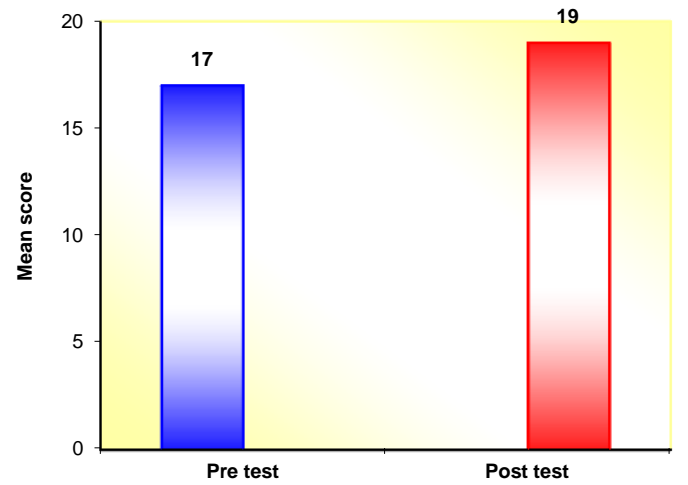

Figure. 2 Distributions of Pretest and Posttest Mean Score of Knowledge on Practice of Mothers

Table 4. Correlation Between Pretest Knowledge and Knowledge on Practice of the Mothers Regarding Prevention of Common Infections Among Infants

\begin{tabular}{|c|l|c|c|c|}
\hline S.No. & \multicolumn{1}{|c|}{ Pretest } & Mean & SD & '(n=40) \\
\hline 1. & Knowledge & 22 & 2.02 & \multirow{2}{*}{+0.127} \\
\hline 2. & Practice & 17 & 1.24 & \\
\hline
\end{tabular}

Table 4 Shows there was a positive correlation between knowledge and knowledge on practice in pretest.

Table. 5. Correlation Between Posttest Knowledge and Knowledge on Practice of the Mothers Regarding Prevention of Common Infections Among Infants

\begin{tabular}{|c|l|c|c|c|}
\hline \multicolumn{1}{|c|}{ Post test } & Mean & SD & 'r' \\
\hline S.No. & & 27 & 1.64 & \multirow{2}{*}{+0.523} \\
\hline 1. & Knowledge & 19 & 0.80 & \\
\hline 2. & Practice & 19 & \\
\hline
\end{tabular}

Table 5 shows there was a hve correlation between knowledge and knowledge on practice in post test.

The association level of post test knowledge of mothers regarding prevention of common infections among infants with selected demographic variables. It revealed that there was no significant association in other variables. But there was association with the diet consumed by the family at the level of $p<0.05$.

The association level of post test knowledge on practice of mothers regarding prevention of common infections among infants with selected demographic variables. It revealed that there was no significant association in other variables. But there was association with the type the family at the level of $p<0.05$.

\section{Conclusion:}

The conclusion of the study was drawn as there was an improvement of knowledge and practice of mothers regarding prevention of common infections among infants after receiving the planned teaching programme.

\section{References:}

[1]. Meharban Singh (1999), Care of the children (5th Edition). New Delhi: Sagar Publishers.

[2]. Kashurisundarao (1995), An introduction to community Health Nursing, $\left(1^{\text {st }}\right.$ Edition.). Chennai: B.I. Publication.

[3]. Donna L Wong (2005) Nursing care of Infants and Children ( $6^{\text {th }}$ Edition), Missouri: Mosby publications.

[4]. Park. K (2002), Text Book Of Preventive And Social Medicine, Jabalpure: M/S Banarsidas Bharat Publishers Badruddin. S.H.et.al (1997)

[5]. Appropriated breast feeding practices. For successful lactation. Journal of obstetrics and Gynaecology 47(2)

[6]. Bajpal smith VD (1998), Welcome Newbaby, Health Action, 9(4).

[7]. Chaturvedi, et al (2000) Knowledge and attitude regarding breast feeding. India founder of Pediatrics 67(4).

[8]. Christensen (1998), Care of Hands and Nails. Indian journal of Nursing, 19 (144).

[9]. Long (2000), Childhood hygienic practices, the community approach Journal of health policy, 33 (6-11). 